\title{
VALIDATION OF AEROSOL PRODUCTS FROM ESA/AATSR OVER CHINA AND AOD FUSION BASED ON UNCERTAINTIES
}

\author{
Yanan Wen ${ }^{1,2}$, Yahui Che ${ }^{1,2}$, Jie Guang ${ }^{1, *}$, Yanqing Xie ${ }^{1,2}$, Zheng Shi ${ }^{1,2}$, Ying Zhang ${ }^{1}$, Zhengqiang Li $^{1}$ \\ ${ }^{1}$ State Environmental Protection Key Laboratory of Satellite Remote Sensing, Institute of Remote Sensing and Digital Earth, \\ Chinese Academy of Sciences, Beijing 100101, China - (guangjie, zhangying, lizq)@aircas.ac.cn \\ ${ }^{2}$ University of Chinese Academy of Sciences, Beijing 100049, China- (m15611670108, 15011546747, x_yanqing, \\ sdustchsz)@163.com
}

Commission III, WG III/8

KEY WORDS: Aerosol, Validation, Fusion, ADV, ORAC, SU, Uncertainty

\begin{abstract}
:
Aerosols play an important role in climate changes and environmental changes as well as on human health. ADV v3.11, ORAC v4.10, and SU v4.32 was three new versions of Advanced Along-Track Scanning Radiometer (AATSR) aerosol datasets which are published on Climate Change Initiative (CCI). In order to evaluate the accuracy of three AATSR aerosol optical depth (AOD) datasets, and to improve the spatial coverage and accuracy of AATSR AOD dataset, this study completed two works: the first part is validated the accuracy of three AOD datasets; the second part is fused three AATSR AOD datasets based on uncertainty of each dataset. After comparing with AERONET and CARSNET ground-based data over China, results show that the root-mean-square error (RMSE) for ADV v3.11, ORAC v4.10, SU v4.32 and fused AOD are 0.22, 0.17, 0.18, 0.17 respectively.
\end{abstract}

\section{INTRODUCTION}

Aerosols play a major role in Earth's climate system, including intervening in the radiation budget and cloud processes (Kaufman et al., 2002; Remer et al., 2005; Tzanis et al., 2008). Aerosol Optical Depth (AOD) is the vertical integral of the aerosol extinction coefficient from the ground to the top of the atmosphere, and it describes the effect of aerosol on light reduction (Michalsky et al., 2009). It is one of the most important parameters in atmospheric aerosol and aerosol remote sensing research (Andreae et al., 2005; Kolmonen et al., 2015; Varotsos and Ghosh, 2017). AOD also plays an important role in many aerosol-related fields, such as aerosol radiative forcing, atmospheric correction of remote sensing images, and monitoring of air quality (Kong et al., 2016; Ma et al., 2016; Mbienda et al., 2016). Therefore, it requires us to rigorously verify the aerosol quality of satellite inversion and improve the coverage and accuracy of aerosol data sets through multiple aerosol product fusion methods, thus providing a high quality for climate change and air quality monitoring research.

Advanced Along-Track Scanning Radiometer (AATSR) is one of the Announcement of Opportunity (AO) instruments onboard the European Space Agency (ESA) satellite ENVISAT. It is in a series of instruments designed primarily to measure Sea Surface Temperature (SST), following on from ATSR-1 and ATSR-2 onboard ERS-1 and ERS-2. AATSR data have a resolution of 1 $\mathrm{km}$ at nadir, and are derived from measurements of reflected and emitted radiation taken at the following wavelengths: $0.55 \mu \mathrm{m}$, $0.66 \mu \mathrm{m}, 0.87 \mu \mathrm{m}, 1.6 \mu \mathrm{m}, 3.7 \mu \mathrm{m}, 11 \mu \mathrm{m}$ and $12 \mu \mathrm{m}$. AATSR is used to observe the Earth in dual view, the data from AATSR can be used to retrieve AOD both over land and ocean. ADV v3.11, ORAC v4.10, and SU v4.32 was three new versions of AATSR aerosol datasets which are published on Climate Change Initiative (CCI) (http://www.esa-aerosol-cci.org/). Note that, this paper focus on AOD at $550 \mathrm{~nm}$ from L2 data even though the participants give some other aerosol properties. This study mainly shows validation results of these three AOD products with AERONET and CARSNET ground-based data over China, respectively. Furthermore, we used a fusion algorithm to combine these three AOD products to improve the coverage and accuracy.

\section{DATA}

\subsection{Satellite Data}

We chose three new versions of the AATSR AOD dataset (ADV v3.11, ORAC v4.10, and SU v4.32), and they are available from Climate Change Initiative (CCI) (http://www.esa-aerosolcci.org/). The details information of three products are as follow:

2.1.1 ADV Algorithm: AATSR Dual View Algorithm (ADV) (Kolmonen et al., 2017) utilizes the measured top of the atmosphere (TOA) reflectance in both the nadir and forward views to decouple the contributions of the atmosphere and the surface to retrieve aerosol properties over land. Over ocean, the surface reflectance is modelled and both views are used independently to retrieval aerosol properties. The resolution of $\mathrm{ADV}$ is 0.1 degree in global range.

2.1.2 ORAC Algorithm: Oxford-RAL Aerosol and Cloud Algorithm (ORAC) (Thomas et al., 2017) is a dual-view aerosol retrieval scheme for use over both land and ocean surfaces. ORAC retrieves both aerosol optical depth and effective radius, as well as the surface reflectance at each of the four AATSR short-wave channels, using a mixture of pre-defined aerosol components. The resolution of ORAC is 0.1 degree in global range.

\footnotetext{
* Corresponding author
} 
2.1.3 SU Algorithm: The SU-ATSR algorithm (SU) (North et al., 2017) is developed by Swansea University to estimate atmospheric aerosol and surface reflectance for the ATSR-2 and AATSR sensors. Over land, the algorithm employs a parameterised model of the surface angular anisotropy, and uses the dual-view capability of the instrument to allow estimation without a priori assumptions on surface spectral reflectance. Over ocean, the algorithm uses a simple model to exploit the low ocean leaving radiance at red and infra-red channels at both nadir and along-track view angles. The resolution of SU is 0.1 degree in global range.

\begin{tabular}{|c|c|c|c|}
\hline Algorithm & Version & Sensor & $\begin{array}{c}\text { Resolution and } \\
\text { coverage }\end{array}$ \\
\hline ADV & 3.11 & AATSR & 0.1 degree, global \\
ORAC & 4.10 & AATSR & 0.1 degree, global \\
SU & 4.32 & AATSR & 0.1 degree, global \\
\hline
\end{tabular}

Table 1. Details of three AATSR AOD products

\subsection{Ground-based Data}

We selected ground-based measurements from both of these two networks as reference data for the purpose of highly accuracy evaluation of these three AATSR L2 AOD products. The spatial distribution of AERONET and CARSNET sites in China is shown as Figure 1.

2.2.1 AERONET Aerosol: It has been demonstrated that the ground-based observation data from Aerosol Robotic Network (AERONET) have the ability and precision to be used as reference data when users validate satellite AOD (Holben et al., 1998). AERONET provides users data at three levels, Level 1.0 (unscreened), Level 1.5 (cloud-screened), and Level 2.0 (cloudscreened and quality-assured). Multiple-bands AOD and derived aerosol properties products are available at the official UBL (https://aeronet.gsfc.nasa.gov/). The latest version of AERONET data is the Version 3 which is used in this paper.

2.2.2 CARSNET Aerosol: CARSNET equips same CE-318 instruments here have 50 observation sites been constructed (Che et al., 2009; Che et al., 2015), more sites and more uniform spatial distribution (in particular where there are no AERONET sites) than AERONET sites in China.

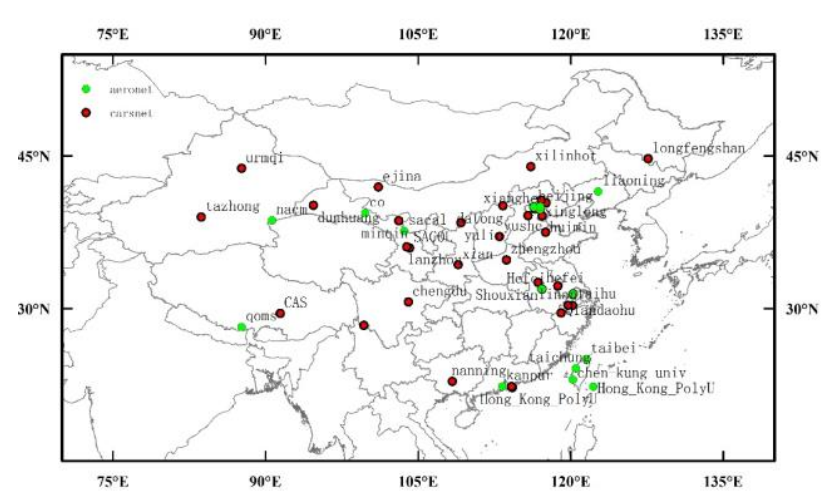

Figure 1. Spatial distribution of AERONET (red points) and CARSNET (green points) sites in China

\section{METHODOLOGY}

\subsection{Spatio-temporal Compare Approach}

To evaluate the accuracy of AATSR AOD dataset, we selected ground-based measurements from AERONET and CARSNET as reference data. The validation method is that comparing averaged ground-based measurements within $\pm 30 \mathrm{~min}$ to satellite overpass time with averaged satellite retrievals from $5 \times 5$ pixels (for L2 dataset) around observation sites (Ichoku et al., 2002). There are at least 5 pixels and 2 ground-based observations are needed when averaging for each comparison.

\subsection{Evaluation Metrics}

3.2.1 MSA: The Mean Satellite-retrieved AOD (MSA), as defined in Eq.1, is the basic parameter for a quick view of satellite-retrieved AOD, as follow:

$$
M S A=\frac{1}{n} \sum_{i=1}^{n} \tau_{s a t, i}
$$

where $\quad n=$ number of valid AOD pixels in $5 \times 5$ window

$$
\tau_{s a t, i}=\text { valid satellite AOD value }
$$

3.2.2 MAA: Mean AERONET or CARSNET AOD (MAA) defined as Eq.2, represents the central tendency of the data, as follow:

$$
M A A=\frac{1}{n} \sum_{i=1}^{n} \tau_{\text {aero,i }}
$$

where $\quad n=$ number of valid AOD within $\pm 30 \mathrm{~min}$ $\tau_{\text {aero }, i}=$ valid AERONET or CARSNET AOD

3.2.3 RMB: The Relative Mean Bias (RMB), which is equal to the ratio of MSA to MAA, as Eq.3, is introduced as a simple indicator of under/over-estimation, as follow:

$$
R M B=\mathrm{MSA} / \mathrm{MAA}
$$

3.2.4 RMSE: The root-mean-square error (RMSE) represent the evaluation metric of the difference between satellite retrievals and ground-based measurements (Levy et al., 2010; Sayer et al., 2014; Che et al., 2016). RMSE represents the sample standard deviation of $\tau_{s a t}-\tau_{A E R}$ as Eq.4. It has great potential to predict model accuracy and precise prediction error when there are no samples, as follow:

$$
R M S E=\sqrt{\left(\frac{1}{n} \sum_{i=1}^{n}\left(\tau_{s a t}-\tau_{A E R}\right)^{2}\right)}
$$

$$
\begin{array}{ll}
\text { where } & n=\text { number of successful matched AOD } \\
& \tau_{\text {sat }}=\text { averaged satellite AOD } \\
\tau_{A E R}=\text { averaged AERONET or CARSNET AOD }
\end{array}
$$

\subsection{Fusion Algorithm}

The fusion algorithm consists of three parts (Xie et al., 2017). The first part is to remove the system errors based on surface reflectance (REF). The second part is to fusion AOD datasets based on uncertainties. The third part is to remove outliers. 
3.3.1 Remove the System Errors: Because of the high correlation between AOD error and AOD and surface reflectivity (REF), we can determine the systematic error from AOD and REF. We divided the AOD into four groups, divided the REF into four groups and calculated the systematic error in each case according to ground-based data.

3.3.2 Calculate the Uncertainty and Fusion of Datasets: In this study, we use RMSE to represent the magnitude of uncertainty. First of all, we calculate the RMSE based on groundbased data of each group according to the above grouping method. Then use RMSE as a weight of the fusion result.

3.3.3 Remove Outliers: We use the standard deviation calculated by the effective value of the $5 \times 5$ pixels window as the standard for evaluating the difference between the pixel and its neighbouring pixels. When the standard deviation of a pixel is greater than a certain threshold, we can remove it as an outlier. In this study, we selected 0.20 as the threshold (Xie et al., 2017).

\section{RESULTS AND ANALYSES}

\subsection{Coverage Comparison}

The spatial coverage of AOD is one of the reference standards for evaluating the quality of AOD product. High coverage AOD products have important application significance in the fields of atmosphere monitor and human health. In this paper, we mainly compared the spatial coverage of three new versions AATSR AOD. Figure 2 shows the annual averaged three AATSR AOD $(550 \mathrm{~nm})$ distributions over China in 2008. We calculated the coverage as effective pixel number divided by total pixel number. We can see that ADV has the smallest coverage at arid or semiarid area in western China like deserts and Qinghai-Tibetan Plateau. The coverage of ORAC in China is 0.912 . ORAC has more coverage over desert regions in Xinjiang region than ADV and in Qinghai-Tibetan Plateau. The coverage of ORAC in China is 0.910 . SU has the largest coverage among the three products in China which equals to 0.938. Even over Qinghai-Tibetan Plateau (extremely low AOD controlled area), the coverage of SU is also optimistic. As shown in Figure 3, fused AOD which combined the characteristics of three AOD datasets is larger than ADV, ORAC and SU. The coverage of fused AOD in China is 0.979.

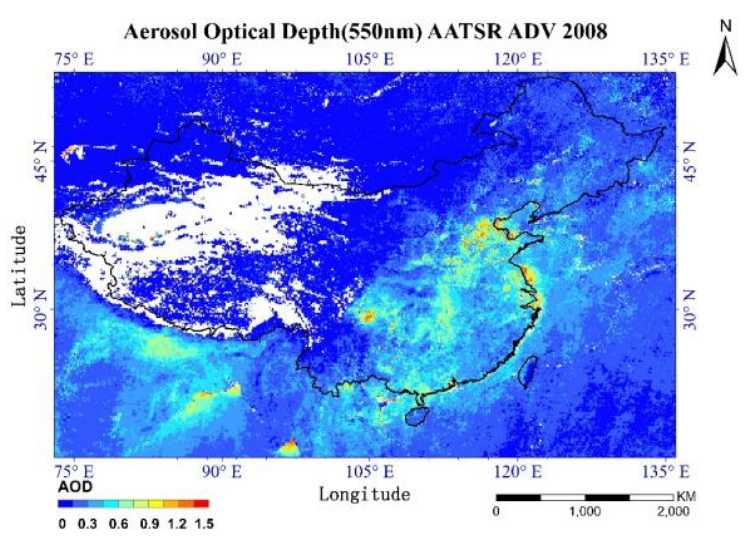

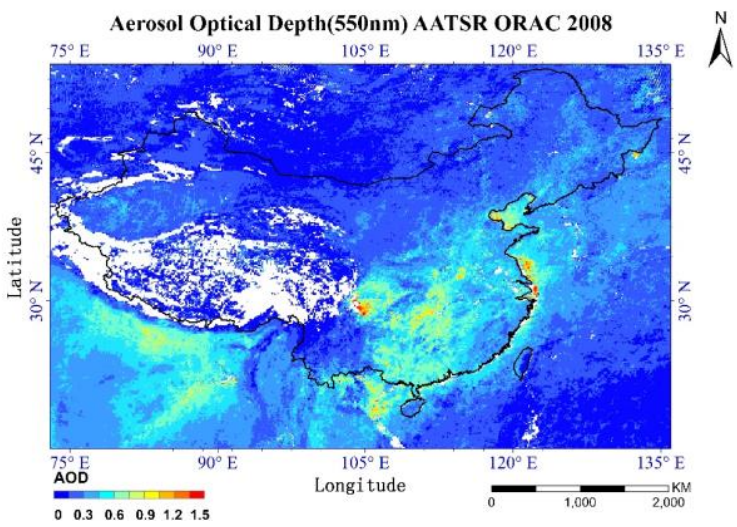

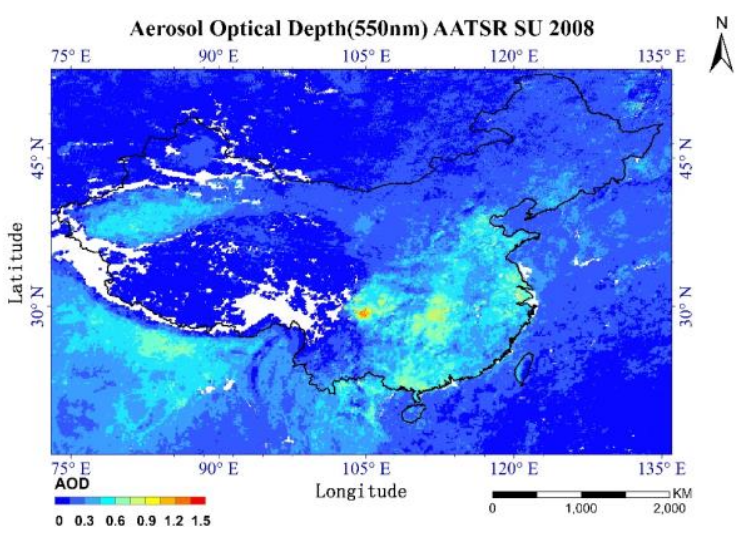

Figure 2. Annual averaged three AATSR AOD (550 nm) (ADV v3.11, ORAC v4.10, and SU v4.32) distributions over China in 2008

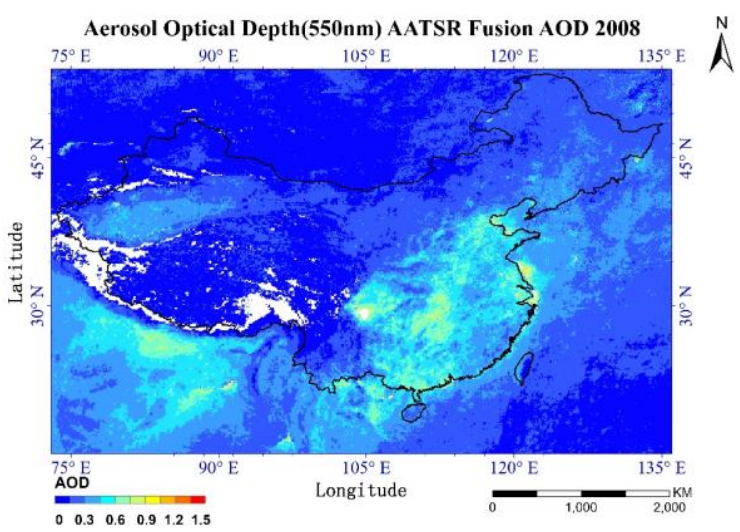

Figure 3. Annual average of fused AOD $(550 \mathrm{~nm})$ distributions over China in 2008

\subsection{Accuracy Comparison}

We used five evaluation metrics: Mean Satellite-retrieved AOD (MSA), Mean AERONET and CARSNET AOD (MAA) and the Relative Mean Bias (RMB), root-mean-square error (RMSE), coefficient correlation (R) to validate the accuracy of three AOD datasets (ADV, ORAC and SU). The detail of statistical result is shown in Table 2. Result shows that ADV has low MSA and high MAA indicating obvious underestimation with low RMB; MSA and MAA of ORAC are close showing slightly underestimate; SU has the same situation with ADV with low MSA and high MAA indicating obvious underestimation. The MSA, MAA and RMB of fused AOD is 0.321, 0.361 and 0.889 , same as ORAC, with slightly underestimate. RMSE for ADV, ORAC, SU and 
fused AOD are 0.22, 0.17, 0.18, 0.17, respectively. R for ADV, ORAC, SU and fused AOD are $0.849,0.835,0.871,0.883$, respectively. In general, the accuracy of fused AOD is obviously superior to the three original datasets.

\begin{tabular}{|c|c|c|c|c|c|c|}
\hline Product & $\mathrm{N}$ & MSA & MAA & RMB & R & RMSE \\
\hline ADV & 352 & 0.317 & 0.439 & 0.732 & 0.849 & 0.22 \\
ORAC & 495 & 0.333 & 0.364 & 0.916 & 0.835 & 0.17 \\
SU & 403 & 0.350 & 0.431 & 0.814 & 0.871 & 0.18 \\
$\begin{array}{c}\text { Fusion } \\
\text { AOD }\end{array}$ & 434 & 0.321 & 0.361 & 0.889 & 0.883 & 0.17 \\
\hline
\end{tabular}

Table 2. Main statistics of the validation results
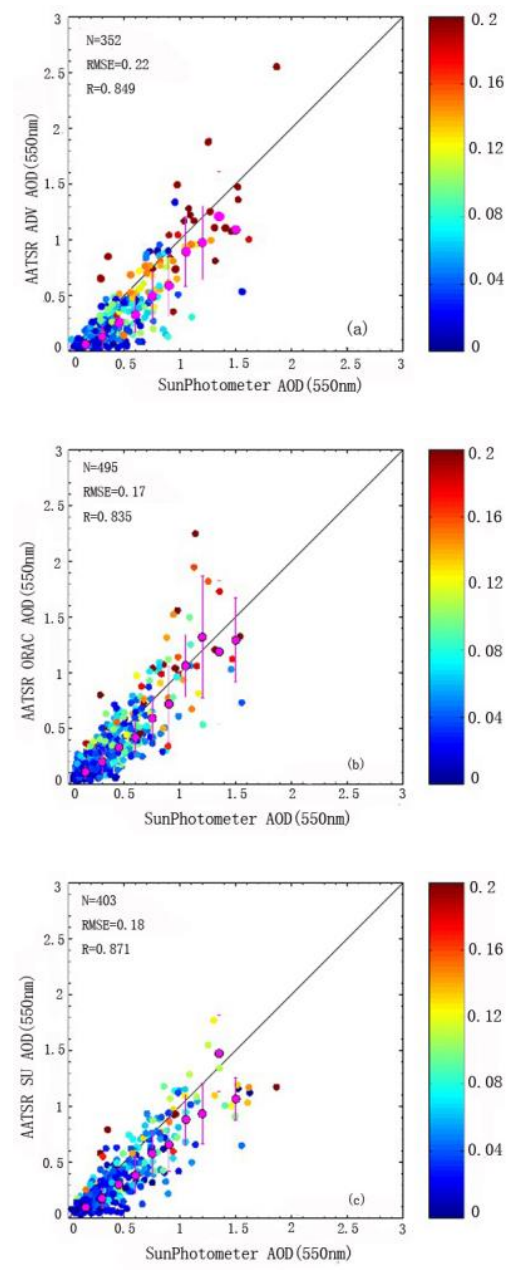

Figure 4. Scatter panels of three AATSR AOD with Sun Photometer AOD (AERONET and CARSNET)

In order to show the validation results more intuitively, we also made scatter panels of AATSR AOD and fusion AOD with Sun Photometer AOD (AERONET and CARSNET). As shown in Figure 4, the black solid line represents the 1-1 line and colors represent standard deviation of AOD within $5 \times 5$ pixels. The magenta points are means for specific ranges of AERONET and CARSNET AOD, and the magenta lines are the mean $\pm 2 \sigma$ of retrievals in a certain range. Colors of ADV get warmer depending on satellite AOD growth; colors of ORAC is colder than ADV showing higher accuracy. Colder colors of SU is twice than other two product even when AOD value is higher than 1.0. Colder colors of fusion AOD is more than warmer colors when
AOD value is little than 1.0. Where AOD value is larger than 1.0, the fusion AOD became a slightly underestimate. That caused by almost these three original AOD are underestimate at high aerosol loading.

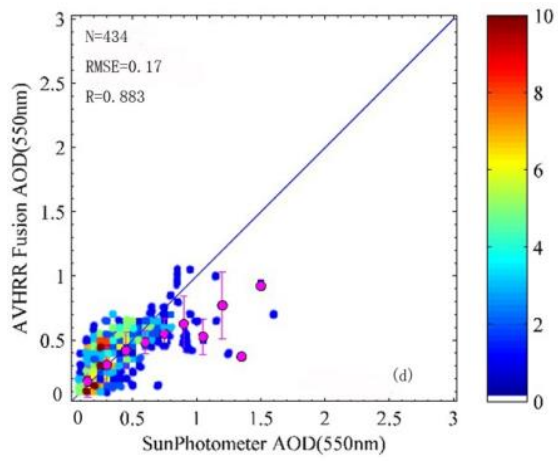

Figure 5. Scatter panels of fused AOD with Sun Photometer AOD (AERONET and CARSNET)

\section{DISCUSION AND CONCLUSION}

In this study, we firstly validated three AATSR AOD datasets (ADV v3.11, ORAC v4.10, SU v4.32) using AERONET and CARSNET. We found that ADV and ORAC almost had no coverage on the Tibetan Plateau, ADV also had little coverage on Xinjiang province. In terms of coverage, $\mathrm{SU}$ is much better than ADV and ORAC. What's more, low MSA and high MAA showing obvious underestimation with low RMB of ADV and SU. As the validation result shows that the spatial coverage of aerosol optical thickness provided by a single sensor for remote sensing is limited and can't provide a full coverage product, but the aerosol datasets form different sensors can complement each other in space. In order to create a more consistency, higher precision and wider spatial coverage aerosol optical thickness product, we fused these three AATSR AOD. The results of the validation show that the accuracy of fusion product is obviously superior to the original data. Therefore, fusion method developed in this paper can effectively improve the coverage and accuracy of AOD datasets.

\section{ACKNOWLEDGEMENTS}

This work was supported in part by the Strategic Priority Research Program of the Chinese Academy of Sciences (grant no. XDA19080303), the Ministry of Science and Technology (MOST) of China under grant nos. 2016YFC0200500, the National Natural Science Foundation of China (NSFC) under grant nos. 41590855, 41871260 and 41471306 . We are thankful to the ICARE for providing access to the AATSR AOD data. Many thanks are due to the AERONET, CARSNET coordination team for organizing and maintaining excellent and essential support for satellite retrieval development and validation.

\section{REFERENCES}

Andreae, M., Jones, C., Cox, P., 2005. Strong present-day aerosol cooling implies a hot future. Nature, 435, 1187-90.

Che, H., Zhang, X., Chen, H., Damiri, B., Goloub, P., Li, Z., Zhang, X., Wei, Y., Zhou, H., Dong, F., Li, D., Zhou, T., 2009. Instrument calibration and aerosol optical depth validation of the China aerosol remote sensing network. J. Geophys. Res., 114(D3), D03206. 
Che, H., Zhang, X., Xia, X., Goloub, P., Holben, B., Zhao, H., Wang, Y., Zhang, X., Wang, H., Blarel, L., Damiri, B., Zhang, R., Deng, X., Ma, Y., Wang, T., Geng, F., Qi, B., Zhu, J., Yu, J., Chen, Q., Shi, G., 2015. Ground-based aerosol climatology of China: aerosol optical depths from the China aerosol remote sensing network (CARSNET) 2002-2013. Atmos. Chem. Phys., 15(8), 7619-7652.

Che, Y., Xue, Y., Mei, L., Guang, J., She, L., Guo, J., He, X., Di, A., Fan, C., 2016. Technical note: Intercomparison of three AATSR level 2 (12) AOD products over China. Atmos. Chem. Phys., 16(15), 9655-9674.

Holben, B., Eck, T., Slutsker, I., Tanré, Buis, J., Setzer, A., Vermote, E., Reagan, J., Kaufman, Y., Nakajima, T., Lavenu, F., Jankowiak, I., Smirnov, A., 1998. AERONET - a federated instrument network and data archive for aerosol characterization. Remote Sens. Environ., 66(1), 1-16.

Ichoku, C., Chu, D. A., Mattoo, S., Kaufman, Y.J., Remer, L.A., Tanré, D., Slutsker, I., Holben B.N., 2002. A spatio-temporal approach for global validation and analysis of MODIS aerosol products. Geophys. Res. Lett., 29(12), 8006.

Kaufman, Y., Tanré, D., Boucher, O., 2002. A satellite view of aerosols in climate systems. Nature, 419, 215-223.

Kolmonen, P., Sogacheva, L., De Leeuw, G., Pinnock, S., Thomas, H., 2017. Aerosol Algorithm Theoretical Basis Document (ATBD) for AATSR Dual View Algorithm (ADV) Algorithm. http://cci.esa.int/sites/default/files/Aerosol_cci2_ ATBD_ATSR_FMI_v4.1.pdf (accessed on 4 September, 2019).

Kolmonen, P., Sogacheva, L., Virtanen, T., de Leeuw, G., Kulmala, M., 2015. The ADV/ASV AATSR aerosol retrieval algorithm: current status and presentation of a full-mission AOD dataset. Int. J. Digit. Earth, 9(6), 545-561.

Kong, L., Xin, J., Zhang, W., Wang, Y., 2016. The empirical correlations between PM2.5, PM10 and AOD in the Beijing metropolitan region and the PM2.5, PM10 distributions retrieved by MODIS. Environ. Pollut., 216, 350-360.

Levy, R., Remer, L., Kleidman, R., Mattoo, S., Ichoku, C., Kahn, R., Eck, T., 2010. Global evaluation of the Collection 5 MODIS dark-target aerosol products over land. Atmos. Chem. Phys., 10(21), 10399-10420.

Ma, X., Wang, J., Yu, F., Jia, H., Hu, Y., 2016. Can MODIS AOD be employed to derive PM2.5 in Beijing-Tianjin-Hebei over China? Atmos. Res., 181, 250-256.

Mbienda, A. J. K., Tchawoua, C., Vondou, D. A., Choumbou, P., Kenfack Sadem, C., Dey, S., 2016. Impact of anthropogenic aerosols on climate variability over central Africa by using a regional climate model. Int. J. Climatol., 37, 249-267.

Michalsky, J., Denn, F., Flynn, C., Hodges, G., Kiedron, P., Koontz, A., Schlemmer, J., Schwartz, S., 2009. Climatology of aerosol optical depth in North-central. J. Geophys. Res., D7, 115.

North, P., Heckel, A., Davies, W., Bevan, S., Grey, W., De Leeuw, G., 2017. Aerosol Algorithm Theoretical Basis Document (ATBD) for AATSR SU Algorithm. http://cci.esa.int/sites/default/files/Aerosol_cci2_ATBD_ATSR _SU_v4.3.pdf (accessed on 4 September, 2019).
Remer, L., Kaufman, Y., Tanré, D., Mattoo, S., Chu, D., Martins,J., Li, R., Ichoku, C., Levy, R., Kleidman, R., Eck, T., Vermote, E., Holben, B., 2005. The MODIS aerosol algorithm, products, and validation. J. Atmos. Sci., 62, 947-973.

Sayer, A., Munchak, L., Hsu, N., Levy, R., Bettenhausen, C., Jeong, M., 2014. MODIS Collection 6 aerosol products: Comparison between Aqua's e-Deep Blue, Dark Target, and "merged" data sets, and usage recommendations. J. Geophys. Res., 119, 13965-13989.

Thomas, G., Poulsen, C., Povey, A., De Leeuw, G., 2017. Aerosol Algorithm Theoretical Basis Document (ATBD) for AATSR Oxford-RAL Aerosol and Cloud (ORAC) Algorithm. http://cci.esa.int/sites/default/files/Aerosol_cci2_ATBD_ATSR _ORAC_v3.0.pdf (accessed on 4 September, 2019).

Tzanis, C. and Varotsos, C., 2008. Tropospheric aerosol forcing of climate: a case study for the greater area of Greece. Int. J. Remote Sens., 29, 2507-2517.

Varotsos, C. A. and Ghosh, S., 2017. Impacts of climate warming on atmospheric phase transition mechanisms. Theor. Appl. Climatol., 130(3-4), 1111-1122.

Xie, Y., Xue, Y., Guang, J., Mei, L., Fan, C., She, L., 2017. Image Fusion of MODIS AOD (Collection 6) in China Based on Uncertainty. 2017 IGARSS, 23-28. 